\title{
Sustainable Optimization of Waste Management Network to Energy Products over Extended Planning Time Horizon
}

\author{
Yousef Saif ${ }^{1}$, Ali Almansoori², and Ali Elkamel ${ }^{3}$ \\ ${ }^{1}$ Khalifa University of Science and Technology \\ ${ }^{2}$ The Petroleum Institute \\ ${ }^{3}$ University of Waterloo
}

November 3, 2020

\begin{abstract}
This study proposes a multiperiod mixed integer linear programming model for the management of a single municipal solid waste (MSW) treatment plant with sustainability as the objective. Discrete and continuous variables define the capacity selections for diverse MSW technologies, and the operation of the MSW network, respectively. The economic target is considered to maximize the net present value. The environmental impact is the minimization of a normalized environmental objective function (NEOF). The social target is the maximization of jobs. An interesting feature about the research work is the requirement of biodrying technologies for MSW moisture content control. Due to the conflicted nature among the sustainability components, a multiobjective optimization (MO) is carried out to find the Pareto optimal solutions. The MO results show that the Pareto optimal solutions vary around profit range of US\$ 4.9-8.5 billion, NEOF impact range of 3.2-3.6 units, and social benefit range of $2700-4828$ jobs.
\end{abstract}

\section{Hosted file}

paper v3.pdf available at https://authorea.com/users/372419/articles/490463-sustainableoptimization-of-waste-management-network-to-energy-products-over-extended-planning-timehorizon

\section{Hosted file}

Figuer list v3.pdf available at https://authorea.com/users/372419/articles/490463sustainable-optimization-of-waste-management-network-to-energy-products-over-extendedplanning-time-horizon

\section{Hosted file}

Table list v3.pdf available at https://authorea.com/users/372419/articles/490463-sustainableoptimization-of-waste-management-network-to-energy-products-over-extended-planning-timehorizon 